\title{
Back in the USSR? Nostalgia soviética na Rússia contemporânea*
}

\author{
Henrique Canary**
}

Resumo: Este artigo examina o fenômeno da "nostalgia soviética" na Rússia contemporânea. Esta nostalgia pode ser definida como sendo o interesse, por parte da população russa, para com a cultura, a estética, o modo de vida e o passado soviético em geral. 0 fenômeno é explicado como parte das transformações ocorridas na memória coletiva do povo russo desde meados dos anos $1990 \mathrm{e}$ que se aprofundaram nos últimos anos. 0 artigo busca também abordar a utilização deste fenômeno por parte do Estado russo no sentido da criação de uma nova ideia nacional russa, baseada na unidade nacional e no patriotismo conservador.

\begin{abstract}
This article examines the phenomenon of "Soviet nostalgia" in contemporary Russia. This nostalgia can be defined as the Russian population's interest in culture, aesthetics, way of life and the Soviet past in general. The phenomenon is explained as part of the transformations that have occurred in the collective memory of the Russian people since the mid-1990s and have deepened in recent years. The article also seeks to address the use of this phenomenon by the Russian state in the sense of creating a new Russian national idea based on national unity and conservative patriotism.
\end{abstract}

Palavras-chave: nostalgia soviética, memória cultural, cultura russa Keyword: soviet nostalgia, cultural memory, Russian culture 
Um menino soviético pergunta para a mãe:

- Mãe, Lenin era bonzinho?

- Era- responde a mãe.

- EStalin?

- Stalin era malvado.

- EBeria?

- Beria também era malvado.

- Ekhruschev?

- Que bobagem, menino, ficar perguntando

'bonzinho ou malvado?',

'malvado ou bonzinho?!" Quando ele morrer, a

gente vai saber!"

(Piada soviética do final dos anos 1950)

*Artigo submetido em 13 de junho de 2017 e aprovado em 26 de agosto de 2017.

**Mestre em História pela Universidade da Rússia da Amizade dos Povos (Moscou) e doutorando do Programa de Pós-graduação em Literatura e Cultura Russa da Faculdade de Filosofia, Letras e Ciências Humanas da Universidade de São Paulo. E-mail: henriquecanary@yahoo.com. br

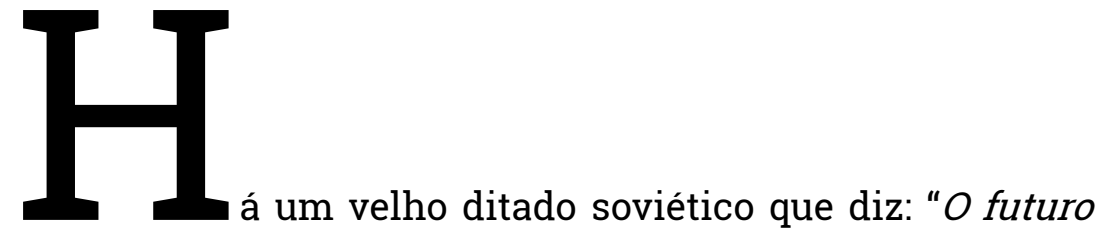

é certo! Já o passado... é imprevisível!". Essa bem-humorada sabedoria popular se refere ao fato de que na União Soviética todos sabiam aonde chegariam: no comunismo. Sobre isso não havia nem poderia haver qualquer dúvida. Por outro lado, cada novo secretário-geral, para se afirmar frente ao seu antecessor, formulava e apresentava à sociedade soviética uma nova visão da história, apagando, relativizando ou, ao contrário, exaltando o papel deste ou daquele evento histórico, deste ou daquele personagem. De repente, a sociedade era informada que os heróis de ontem haviam sido desmascarados como "inimigos do povo" (como ocorreu, por exemplo, com toda a velha guarda do partido bolchevique, perseguida e morta por Stalin nos anos 1930). Ou o contrário: descobria-se que os antigos opressores se haviam revelado amigos e aliados confiáveis (como ocorreu com a Alemanha nazista depois da assina- 
tura do Pacto Hitler-Stalin¹, em 1939, e até mesmo - fato pouco conhecido - com uma figura odiosa como Ivan, o Terrível, que unificou a ferro e sangue as terras russas no século 16 e cuja imagem foi reconstruída por Stalin) ${ }^{2}$.

A memória histórica do povo era a mais importante arena de batalha ideológica na sociedade soviética. Talvez em todas as sociedades. Mas foi na URSS que esta batalha se desenvolveu com todo o seu potencial. Neste sentido, a relação da sociedade russa contemporânea com o passado soviético permanece objeto de acaloradas discussões, intensas lutas políticas e sociais, debates religiosos e culturais.

O "degelo" dos anos 1960 (abertura democrática limitada promovida por Khruschev) foi marcado, entre outros elementos, por uma revisão do passado. Mais concretamente, por uma condenação parcial dos crimes de Stalin e uma reabilitação, também parcial, de seus opositores. ${ }^{3} \mathrm{O}$ mesmo fenômeno se repetiu na "glasnost" de Gorbatchev. No final dos anos 1980, uma série de autores e personagens históricos antes condenados foram parcialmente reabilitados. Foi o caso de alguns intelectuais emigrados (por exemplo, Alexander Soljenitsin, autor de Arquipélago Gulag) e de vários personagens ligados à curta etapa democrático-burguesa da Rússia (fevereiro a outubro de 1917). Outras figuras - mais perigosas para o regime burocrático - foram apenas reconhecidas como "existentes", mas não reabilitadas. Foi o caso de Trótski e de outros dirigentes do núcleo próximo a Lenin.

\footnotetext{
1 Também conhecido como "Pacto Molotov-Ribbentrop", pelo nome dos ministros das relações estrangeiras da URSS e Alemanha na época. Ao contrário da versão divulgada pelo stalinismo durante muitas décadas, o pacto Hitler-Stalin era muito mais do que um acordo de não-agressão. Ele incluía também cláusulas secretas sobre uma possível invasão alemã da Polônia e uma possível invasão soviética da Finlândia. A assinatura do tratado mudou completamente a relação dos partidos comunistas do mundo inteiro com a Alemanha nazista. Os PC's, que vinham denunciando fortemente a política de Hitler, voltaram suas baterias contra o imperialismo francês e britânico, causando assim uma enorme confusão no movimento operário internacional.

2 Sobre a reconstrução da imagem de Ivan IV, o Terrível, é interessante assistir "Ivan, o Terrível" (1944), de Serguei Eisenstein, filme produzido sob encomenda direta de Stalin.

${ }^{3}$ É característico, por exemplo, que o famoso "Informe de Khruschev ao XX Congresso do PCUS" (1956) , ao mesmo tempo em que revelava uma série de crimes cometidos por Stalin, reconhecia como um de seus "méritos" a "luta contra o trotskismo".
} 
Apesar de não ter ocorrido uma reabilitação completa, a simples legalização do pensamento marxista crítico no final dos anos 1980 teve um importante impacto sobre a sociedade soviética. O interesse pelas lutas internas do partido bolchevique (principalmente aquelas travadas na segunda metade dos anos 1920) aumentou súbita e enormemente, e muitas obras foram redescobertas e reeditadas. Assim, por exemplo, uma parte importante das principais obras de Trótski foi publicada na União Soviética (inclusive pelas editoras estatais) entre 1989 e 1991. Também viram a luz trabalhos de Bukhárin, Rakovski, Lunatchárski e outros, bem como alguns escritos de trotskistas ocidentais, como Ernest Mandel.

No entanto, este fenômeno altamente progressivo não durou muito. Com o fim da URSS, tudo o que era "soviético" passou a ser condenado. A vitória de um setor abertamente pró-liberal da burocracia (Ieltsin) foi causa e efeito de uma guinada também na opinião pública. As publicações praticamente cessaram, as ideias de todos os dirigentes bolcheviques, de Trótski a Stalin, foram colocadas no mesmo saco e condenadas pelo liberalismo triunfante. Essa situação se manteve mais ou menos até o final dos anos 1990, quando a "guerra da memória" (como é chamada, na Rússia, essa batalha ideológica) entrou em uma nova fase, denominada por alguns autores de "Renascença da antiguidade soviética"4, e que se estende até hoje.

\section{A nostalgia soviética}

Svetlana Aleksiévitch, Prêmio Nobel de Literatura em 2015, em seu livro mais importante, $O$ fim do homem soviético, assim resumiu essa espécie de "reciclagem" da União Soviética no imaginário popular russo:

Há um novo apelo pela União Soviética. Pelo culto a Stálin. Metade dos jovens de dezenove a trinta anos considera Stálin "um grande político". Num país em que Stálin aniquilou mais pessoas do que Hitler, um novo culto a Stálin?! Tudo que é soviético está de novo na moda. Por exemplo, os cafés "soviéticos", com nomes soviéticos e comida soviética.

${ }^{4}$ PARFENOV, 2008. 
Apareceram doces "soviéticos" e kolbassa "soviética", com o cheiro e o gosto que conhecíamos desde a infância. E, claro, a vodca "soviética". Na televisão, dezenas de programas, e na internet dezenas de sites de nostalgia "soviética". Você pode visitar como turista os campos stalinistas - Solovkí, Magadan. O anúncio afirma que, para uma sensação plena, você vai receber um macacão de campo, uma picareta. Mostram os barracões restaurados. E no fim organizam uma pescaria...

Ideias antiquadas estão de volta: do Grande Império, da "mão de ferro", do "caminho peculiar da Rússia"... Restituíram o hino soviético, existe um Komsomol, só que ele se chama $N a ́ c h r^{5}$, existe o partido do poder, que copia o partido comunista. O presidente tem o mesmo poder do secretário-geral. Absoluto. Em vez do marxismo-leninismo, a Igreja ortodoxa...

\section{[...] Chegou a época do second-hand. ${ }^{7}$}

A expressão "second-hand" é sintomática da ideia aqui apresentada por Aleksiévitch. ${ }^{8}$ A nostalgia por tudo que seja soviético é um fato de grandes proporções hoje na Rússia. Este fenômeno abarca tanto a vida econômica, social e política, quanto as manifestações culturais. Passemos a alguns exemplos: desde 2000, o Hino Nacional da Rússia foi definido como sendo a junção da antiga melodia do Hino da União Soviética com uma nova letra; apesar da enorme visibilidade dada à remoção de alguns monumentos soviéticos no início dos anos 1990, a maioria deles permanece em seus lugares históricos, sendo que alguns, inclusive, vêm sendo restaurados; entre eles, o Mausoléu de Lenin, localizado na Praça Vermelha, e que a Igreja Ortodoxa tentou retirar sem sucesso no final dos anos 1990; foi restabelecida a parada militar de 7 de novembro, aniversário da Revolução de Outubro (pelo calendário gregoriano), na Praça Vermelha, com um protocolo muito similar

\footnotetext{
${ }^{5}$ Uma espécie de salame, muito característico do período soviético.

'Em russo, "Os nossos".

${ }^{7}$ ALEKSIÉVITCH, 2016, p. 29

8 "O fim do homem soviético" é uma tradução não-literal do título original do livro de Aleksiévitch. A tradução literal seria "A hora do second-hand" (Время секонд хэнд), em referência às lojas de artigos de segunda mão, muito populares na Rússia pós-soviética.
} 
ao dos tempos soviéticos; todas as pesquisas de opinião são unânimes em apontar a visão positiva que a maioria dos cidadãos russos tem do passado soviético; Stalin continua sendo um dos personagens históricos mais respeitados, considerado pela população como responsável pela vitória do Exército Vermelho na Segunda Guerra Mundial; as mesmas pesquisas apontam uma ampla preferência dos russos pelo socialismo em detrimento do capitalismo (algumas pesquisas apontam taxas de até $74 \%$ de preferência pelo modelo soviético de sociedade em comparação com o modelo capitalista). ${ }^{9}$

A cultura é outro terreno onde a nostalgia soviética se manifesta com grande força. Desde pelo menos meados dos anos 2000 , nos principais canais da TV russa, houve uma verdadeira explosão de programas e séries em torno da temática soviética. A seguir, alguns destes programas, com seus nomes em tradução livre:

Entretenimento, música e dança: "Patrimônio da República", "Os melhores anos das nossas vidas", "Show de estilos", "Olá novamente!", "Cantado na URSS", "Risada nostálgica", "História do show business russo", "Que anos os nossos!", "Velho apartamento", "Mercado de pulgas", "Velhas canções sobre o que mais importa", "Velha televisão".

Documentários e programas históricos. "Recentemente", "Kremlin 9", "Crônicas históricas", "O julgamento do tempo", "História soviética", "Para que lembrem", "Em busca do que foi perdido", "Como eles se foram", "Investiga-se”, "Império soviético".

Séries de ficção: "Jardim de Alexandrov", "Posto avançado Jilina", "Caçada a Beria", "Saga moscovita", "Extermínio", "Isaev", "Apóstolo", "As nove vidas de Nestor Makhno", "Os filhos da Rua Arbat", "O testamento de Lenin", "Stalin. Live" etc.

\footnotetext{
${ }^{9}$ Notemos desde já que esta pesquisa tende a enganar o analista desavisado. 0 cidadão médio russo "prefere" o socialismo ao capitalismo, como comprovam todas as pesquisas, mas o que se entende por "socialismo" varia muito. Em geral, o termo é associado ao poderio econômico e militar do país e às garantias sociais dadas à população, bem como a alguns valores morais, como a solidariedade e a simplicidade. Ou seja, o conceito de "socialismo" no imaginário popular russo não inclui os elementos estruturais (economia nacionalizada e planificada, inexistência de burguesia) e ideológicos (luta de classes, revolução proletária) característicos do socialismo científico, tal como foi desenvolvido por Marx.
} 
Por sua vez, o cinema russo dos últimos anos tem sido um indicador importante do nível de nostalgia vivido pela população, com dezenas de títulos dedicados ao passado soviético, principalmente à Segunda Guerra Mundial, ou Grande Guerra Patriótica, como ela é chamada na Rússia. Alguns dos principais: "A estrela" (Zvezda, 2000), de Nikolai Lebedev; "Franz e Polina" (Frantz + Polina, 2006), de Mikhail Segal; "A resistência" (Bretskaia krepost, 2010), de Aleksandr Kott; "Somos do futuro" (Mi iz budushego, 2008), de Andrei Maliukov; "Cansados pelo Sol: Antecipação" (Utomlennie solntsem: Predstoianie, 2010), de Nikita Mikhalkov; "Rjev: A batalha desconhecida de Georgui Jukov" (Rjev: Neizvestnaia bitva Georguia Jukova, 2009), de Serguei Numamed; "O cosmos como pressentimento" (Kosmos kak predtchuvstvie, 2005), de Aleksei Utchitel, "Uma lebre sobre o abismo" (Zaiats nad bezdnoi, 2006), de Tigran Keosaian, e muitos outros.

Além dos meios de comunicação tradicionais, como observa a própria Aleksiévitch, a internet tem sido um espaço decisivo de armazenamento, divulgação e discussão sobre a nostalgia soviética, com inúmeros portais e fóruns de debate sobre o tema. Entre os principais projetos, poderíamos citar: "Museu do século 20", (http://20th.su/), "Enciclopédia de nossa infância" (http://e-n-d.ru/), "Vida soviética" (http://soviet-life.livejournal.com/), "Sótão da URSS" (http://cherdak-ussr.livejournal.com/), "Nossa infância" (http://nashe-detstvo.livejournal. com/), "Museu dos anos 70" (http://ru-museum70.livejournal. $\mathrm{com} /$ ).

A nostalgia penetra também o comércio e os serviços. Renascem as marcas tradicionais soviéticas de vodca, sorvete, suco, embutidos, iogurte, cerveja etc. Qualquer coisa que lembre "o cheiro e o gosto" da infância e juventude de milhões de russos. O mesmo acontece nos serviços. Cafés, bares e restaurantes com nomes como "URSS", "soviético", "nostalgia", "socialismo" e vários outros. Em geral, são estabelecimentos sem qualquer vinculação ideológica, que buscam apenas reproduzir o ambiente e a estética soviéticos. 


\section{A origem do fenômeno}

Se retornarmos um pouco no tempo, perceberemos que não é a primeira vez que a nostalgia por um passado considerado glorioso adquire peso de massas na Rússia. Desde pelo menos meados do século 19 até o início do século 20, a relação com o próprio passado esteve no centro dos debates culturais, filosóficos, políticos e históricos da intelligentsia russa. Naquele período, o aumento do interesse pelo passado visava resolver a crise de identidade que a sociedade russa vivia desde as reformas modernizadoras e ocidentalizantes de Pedro I, no início do século 18. Esse debate se materializou no enfrentamento entre ocidentalistas e eslavófilos a partir dos anos 1840, e entre populistas e marxistas a partir de meados dos anos 1870: As discussões apaixonadas, tensas sobre o passado histórico eram um sintoma da formação de diferentes projetos de identidade coletiva: entendia-se então que a sociedade, heterogênea no plano nacional, social e cultural, precisava de uma ideia unificadora, mas encontrar essa ideia não era algo fácil".10

Algo similar vem acontecendo na Rússia hoje. Até o final da década de 1990, a tentativa de construir uma ideia nacional passava essencialmente pela reconstrução dos vínculos culturais e civilizacionais com o passado czarista ${ }^{11}$. Consequentemente, a ideia daquilo que é soviético adquiriu um sentido negativo, uma vez que simbolizava a relação do povo com o Estado soviético, sua economia deficitária e seu sistema político antidemocrático.

Esta realidade começou a mudar desde meados dos anos 1990, quando ficou evidente para a maioria da população russa que o liberalismo econômico e a democracia política de tipo ocidental não cumpririam as promessas feitas na época da perestroika e no início dos anos 1990. Desde então, o anticomunismo vem perdendo rapidamente espaço, o que se reflete num maior interesse pela história soviética, sua cultura, sua estética, seus símbolos.

\footnotetext{
${ }^{10}$ LEONTIEV, 2011, p. 19.

${ }^{11}$ Cf. MORABITO, 2013, p. 61.
} 
É importante observar que não se trata de um renascimento político ou ideológico do comunismo, mas de um fenômeno essencialmente existencial e humano, de uma busca por ideias que possam preencher o vazio espiritual e moral deixado pela crise dos anos 1990. Para Rezanova:

[...] o cidadão da época pós-soviética, por se encontrar em uma atmosfera asfixiante de carência espiritual e déficit de ideais positivos, sente saudade dos valores soviéticos, que preenchiam a vida do cidadão soviético ao fornecer-lhe fé na razão, na liberdade e na irmandade de todas as pessoas. ${ }^{12}$

Aleksiévitch corrobora este ponto de vista quando escreve:

A civilização soviética... Tenho pressa para gravar seus rastros. Rostos conhecidos. Não faço perguntas sobre o socialismo, mas sobre o amor, o ciúme, a infância, a velhice. Sobre música, danças, penteados. Sobre os milhares de detalhes de uma vida que vai desaparecendo. Essa é a única maneira de enquadrar a catástrofe no contorno do cotidiano e de tentar contar alguma coisa. De compreender alguma coisa. ${ }^{13}$

Kupina e Mikháilova (2009), apoiando-se em pesquisas de opinião realizadas pelo instituto de pesquisas Levada Tsentr, de Moscou, fizeram um levantamento sobre quais são, exatamente, os objetos de nostalgia do povo russo. 0 resultado foi revelador. Em primeiro lugar, as pessoas sentem saudades das grandes conquistas da sociedade soviética; em segundo, de aspectos isolados do cotidiano, como as conversas na cozinha e as piadas; em terceiro, da proteção social oferecida pelo Estado, como a saúde e a educação gratuitas; em quarto, dos valores predominantes nas relações pessoais, como o espírito coletivo, a união pacífica, a amizade; em quinto, das conquistas culturais como o cinema e o balé.

No que diz respeito à localização temporal da nostalgia soviética, o que predomina é a saudade da década de 1970, por ser considerado o período de maior estabilidade econômica e social na história da URSS e também a época em que

12 REZANOVA, 2011, p. 59.

${ }^{13}$ ALEKSIÉVITCH, 2016, p. 24. 
a produção de bens encontrou relativo florescimento, permitindo uma maior diversificação do consumo das famílias.

Kupina e Mikháilova chamam atenção para o fato de que a nostalgia é fruto de um trauma civilizacional, provocado pelo desmoronamento repentino de um modo de vida estável e pela perda de enormes conquistas sociais por parte de uma parcela importante da população. Rezanova corrobora este ponto de vista ao falar de "vencidos e vencedores":

Para construir uma vida boa, obviamente, é melhor ser vencedor. Mas os vencidos têm que continuar vivendo também. Esta questão é particularmente importante para os russos, que, desde 1991, se encontram em um estado de derrota. A substituição do marxismo pela filosofia existencialista é um produto dessa época. (REZANOVA, 2011, p. 35)

O que parece fora de dúvidas é o fato de que as crises de identidade coletiva são características das épocas de transição, como a que ainda vive a Rússia. Isso é particularmente verdade quando as mudanças vividas pelo país incluem o desmoronamento de toda a visão de mundo antes predominante na sociedade, quando ocorre a perda do centro de autoridade da nação. Por isso, os últimos 25 anos da história russa transformaram o problema da identidade nacional em um problema universal, que penetra todas as esferas da vida do país.

Ao explicar por que a nostalgia soviética surge exatamente agora, Rezanova afirma que se trata de uma combinação de fatores: "[...] pode-se dizer que a sociedade superou a 'distância' temporal e histórica mínima, depois da qual a irritação é substituída pela curiosidade, pela 'observação', pela tentativa de definir de maneira independente sua própria relação com o fenômeno"14.

Além disso, incide sobre o fenômeno o fator geracional: por um lado, estão vivos ainda aqueles que viveram a maior parte de sua vida na URSS, que dedicaram a ela seus melhores anos e viveram o período de maior estabilidade do país e que hoje se encontram, em sua maioria, em uma situação social e econômica difícil (aposentados, pensionistas, veteranos de guer-

${ }^{14}$ REZANOVA, 2011, p. 126. 
ra); por outro, entra em cena uma geração mais jovem, nascida no final dos anos 1970, que viveu sua infância na URSS, mas que teve destinos muito diferentes do ponto de vista social e econômico e que se encontra hoje no auge de sua vida ativa. Os indivíduos dessa geração não têm nenhuma outra identidade comum a não ser o fato de terem sido a última geração de crianças soviéticas e de terem apenas uma fraca lembrança das dificuldades enfrentadas nos anos 1980.

Também neste tema, o livro de Aleksiévitch é esclarecedor. Ela declara pertencer a uma geração intermediária de cidadãos soviéticos, e afirma:

Eu dividiria os soviéticos em quatro gerações: a de Stalin, a de Khruschóv, a de Brêjniev e a de Gorbatchóv. Sou dessa última. Para nós foi mais fácil aceitar o colapso do ideal comunista, já que não tínhamos vivido naquela época em que o ideal era jovem, forte, com a magia daquele romantismo funesto e daquelas esperanças utópicas ainda não dissipadas. Crescemos na época dos anciãos do Krémlin. Em tempos vegetarianos, de jejum. ${ }^{15}$

\section{O papel do Estado russo}

Dizer que a nostalgia soviética é um fenômeno espontâneo não significa minimizar a importância da intervenção do Estado em todo o processo. Isso é assim porque essa nova visão de mundo, de Rússia e do destino do povo russo se manifesta hoje também em uma política de Estado, que se apoia na nostalgia soviética para promover o patriotismo, o militarismo e uma compreensão muito particular de "unidade nacional". A orientação em direção ao ocidente, predominante nos meios estatais nos anos 1990, vem sendo substituída pela ideia de uma caminho próprio, russo, profundamente patriótico, cristão ortodoxo e nacionalista. Segundo Ilia Kalinin,

[...] a ideia patriótica foi pela primeira vez acionada de maneira explícita ainda em 2003, ou seja, ainda durante o primeiro mandato presidencial de Putin. Na época, após uma

${ }^{15}$ ALEKSIÉVITCH, 2016, p. 23. 
visita a Staraia Ladoga, ${ }_{1}^{16}$ o presidente formulou de maneira precisa a base da nova ideia nacional: "O patriotismo deve se tornar a ideologia unificadora da Rússia". ${ }^{17}$

Essa visão do patriotismo como uma nova ideia nacional russa vem sendo desenvolvida desde então. Para tanto, são colocados em movimento não apenas a herança soviética, mas também a herança imperial e czarista. Em 2005, em sua mensagem anual à Assembleia Federal, Vladimir Putin reconheceu que "[...] o fim da União Soviética foi a maior catástrofe geopolítica do século. Já para o povo da Rússia, foi um verdadeiro drama"18. Mais tarde, em 2008, o presidente Dmítri Medvedev definiu o patriotismo como "[...] a fé na Rússia, a conexão profunda com a terra natal, com nossa grande cultura"19.

É interessante notar que a anexação da Crimeia à Rússia em março de 2014 e o apoio político prestado por Moscou às regiões de Donetsk e Lugansk, que desejam se independentizar da Ucrânia, são justificados principalmente com argumentos que apelam à cultura e à memória: defesa do idioma russo, da ortodoxia cristã e do direito à livre expressão e manifestação cultural. Nas palavras do próprio Vladimir Putin:

[...] na Crimeia vive a nossa gente, e o próprio território tem importância estratégica porque exatamente ali se encontra a fonte espiritual que formou a nação russa, multifacetada e monolítica ao mesmo tempo, bem como o Estado russo centralizado. Pois foi justamente ali, na Crimeia, na antiga Quersoneso, ou, como a chamavam os antigos cronistas russos, Korsun, que o príncipe Vladimir foi batizado e depois batizou toda a Rus ${ }^{20}$.

Junto com a proximidade étnica, idiomática e cultural, junto com a então nascente atividade econômica comum, ainda que em um território não totalmente definido por fronteiras sólidas, e junto com o poder do príncipe, o cristianismo foi uma enorme força espiritual unificadora, que per-

\footnotetext{
${ }_{16}$ Região do noroeste da Rússia, considerada um dos centros originadores do Estado russo.

17 KALININ, 2011.

18 PUTIN, 2005.

${ }^{19}$ Apud KALININ, 2011.

${ }^{20}$ Antiga denominação da Rússia.
} 
mitiu incluir na formação da nação russa unificada e do Estado russo as mais diversas tribos e uniões tribais de todo o mundo eslavo oriental. E exatamente neste território nossos antepassados, pela primeira vez e para sempre, se perceberam como um único povo. $E$ isso nos permite afirmar que a Crimeia, a antiga Korsun, Quersoneso, Sebastopol possuem para a Rússia um enorme valor civilizacional e religioso, da mesma forma que o Monte do Templo em Jerusalém para aqueles que professam o islã ou o judaísmo. É exatamente assim que nós vamos encarar a questão de agora em diante e para sempre. ${ }^{21}$

Como se pode ver, a Rússia vive hoje uma enorme transformação no campo da memória histórica. O governo russo tenta unir todo o passado russo em uma única linha temporal homogênea, teleológica, não-contraditória e não sujeita a debates, servindo assim como base para a unidade absoluta da nação. Ou seja, a nostalgia soviética é apenas a parte mais visível do movimento que ocorre neste momento na memória histórica do povo russo. Na verdade, trata-se de um fenômeno mais profundo, que engloba uma revisão de todo o passado russo.

Para Ilia Kalinin, o que ocorre hoje na Rússia é uma tentativa de usar o sentimento nostálgico da população com um objetivo de longo prazo: construir um novo patriotismo russo, onde o "soviético" é apenas mais um componente. Segundo este raciocínio, o Estado russo apenas se apoia na nostalgia soviética como experiência real da população, como sentimento mais evidente, mais superficial, mais facilmente identificável e manobrável:

Nós estamos lidando não com uma nostalgia pura ou uma intenção de recuperar o objeto perdido, mas sim com uma política voltada para a recodificação positiva da nostalgia pelo passado soviético em um novo patriotismo russo, no qual o soviético não possui praticamente nenhuma especificidade histórica, sendo parte da mesma herança cultural comum. ${ }^{22}$

\footnotetext{
21 PUTIN, 2014.

22 KALININ, 2011.
} 
Essa visão mais profunda do fenômeno da nostalgia soviética é confirmada pelo discurso do próprio presidente Putin:

Para o renascimento da consciência nacional, devemos unir as épocas históricas em uma só e voltar à compreensão da simples verdade de que a Rússia não nasceu em 1917 e nem mesmo em 1991, de que nós temos uma história milenar única, indivisível, através da qual obtemos força interior e damos sentido ao desenvolvimento nacional. ${ }^{23}$

Para Kalinin (2015), a política do Estado russo no terreno da memória histórica e o seu apelo ao passado comum não tem outro objetivo a não ser o de preservar o status quo presente, que é apresentado como uma herança comum que precisa ser mantida. O passado, segundo esta visão estatal, não deve ser interpretado, criticado ou problematizado. Apenas aceito, lembrado, preservado e transmitido.

Essa visão do passado russo como um terreno não passível de discussão se expressa com maior intensidade na questão do papel da Rússia na Segunda Guerra Mundial. A TV, o cinema e as prateleiras das livrarias russas estão repletas de filmes, programas e livros sobre a guerra, mas não se trata, com raras exceções, de qualquer debate ou abordagem crítica, mas sim da criação de vínculos emocionais com o período. Jamais a reflexão racional. Segundo Ushakin,

[...] as comemorações públicas sobre a Grande Guerra Patriótica não são, como regra, exatamente lembranças, mas sim uma espécie de vivência da guerra por pessoas que não tiveram com ela uma relação direta. Ou seja, é um tipo de vivência mediada, uma imersão num contexto superado para construir com este passado uma certa relação emocional. ${ }^{24}$

É claro que, diante de uma tal relação com a guerra (e com a história em geral), toda crítica ou compreensão alternativa do passado será desqualificada como não-russa, não-patriótica, e condenada em nome da preservação da herança cultural comum.

${ }^{23}$ PUTIN, 2012.

${ }^{24}$ USHAKIN, 2015. 


\section{Conclusão: essência e aparência}

Pelo exposto, conclui-se que a nostalgia soviética não tem absolutamente nada a ver com qualquer "giro à esquerda" da sociedade russa (e muito menos de Putin), nem com qualquer renascimento político-ideológico do marxismo no território do antigo império dos tsares. Ao contrário, o fenômeno se insere em um giro conservador mais abrangente e profundo. Junto com a nostalgia soviética, que tanto encanta alguns setores da esquerda stalinista que visitam a Rússia ou acompanham alguns sites russos, segue predominando na Rússia uma opinião pública de direita, extremamente reacionária, não apenas no terreno dos costumes, mas também na política, nas relações internacionais, inter-religiosas e inter-étnicas. A Rússia que restabeleceu o Hino da URSS com uma nova letra é a mesma que "suspendeu" as paradas do orgulho LGBT por cem anos no país; a Rússia que mantém as estrelas de rubi no alto das torres do Kremlin é a mesma que condenou criminalmente três jovens que decidiram filmar um clipe de punk-rock no interior de uma igreja ortodoxa; o Estado russo que exalta o papel do Exército Vermelho na vitória sobre a Alemanha nazista é o mesmo que encarcera até os opositores mais moderados. Com a bandeira vermelha em punho, quem está despertando, na verdade, é o gendarme europeu do século XIX, a ponta de lança da reação, a velha prisão dos povos. Prova disso é o fato de que o pensamento crítico que a seu tempo ofereceu uma explicação e uma saída para a URSS - o pensamento político de marxistas como Leon Trótski - continua semi-banido. $\mathrm{Na}$ melhor das hipóteses, tolerado. As organizações da esquerda não-stalinista levam uma existência muito difícil na Rússia atual. Suas ideias são consideradas utópicas e até infantis. Os "novos russos", burocratas de Estado e conservadores em geral zombam do socialismo durante a tarde, mas se divertem à noite no restaurante "Buffet Especial", cuja entrada principal ostenta uma enorme foto do "camarada Brejnev" em um de seus momentos raros de descontração. 


\section{Referências Bibliográficas}

ALEKSIÉVITCH, S. O fim do homem soviético. São Paulo: Companhia das Letras, 2016, p. 29.

KALININ, I. Kulturnaia politika kak instrument demodernizatsii. (Política cultural como instrumento de desmodernização). 2015. Revista eletrônica "Neprikosnovennii zapas". Disponível em: <http://polit.ru/article/2015/02/15/cultural_policy/>. Acesso em: 21 fev. 2017.

KALININ, I. Nostalgic Modernization: the Soviet Past as "Historical Horizon". (Modernização nostálgica: o passado soviético como "horizonte histórico"). Slavonica, Leeds, n. 2, p. 156-166, nov. 2011.

KUPINA, N. A.; MIKHÁILOVA, O. A. (Org.). Sovetskoe proshloe $i$ kultura nastoiashego. (Passado soviético e cultura do presente). Ekaterimburgo: Izdatelstvo Uralskogo Universiteta, 2009. 640 p. 2 v.

LEONTIEV, O. B. Istoritcheskaia pamiat i obrazi proshlogo $\mathrm{V}$ rossiiskoi kulture XIX - natchala XX vV. (Memória histórica e imagens do passado na cultura russa do século XIX início do século XX) Samara: Kniga, 2011, p. 19.

MORABITO, F. A Rússia pelo cinema de Nikita Mikhalkov. 2013. $171 \mathrm{f}$. Dissertação (Mestrado) - Curso de Literatura e Cultura Russa, Departamento de Letras Orientais, Universidade de São Paulo, São Paulo, 2013, p. 61.

PARFENOV, L. Televidenie nashe iavliaetsia vlastnim piarom (Nossa televisão é um poderoso public relations - Entrevista). 2008. Disponível em: <http://sobesednik.ru/publications/ sobesednik/2008/12/47/parfenov-47-2008>. Acesso em: $20 \mathrm{fev}$. 2017.

PUTIN, V. Poslanie Prezidenta Federalnomu Sobraniu. (Mensagem do Presidente à Assembleia Nacional). 2005. Disponível em: <http://kremlin.ru/events/president/transcripts/22931>. Acesso em: 24 fev. 2017.

PUTIN, V. Poslanie Prezidenta Federalnomu Sobraniu. (Mensagem do Presidente à Assembleia Nacional). 2012. Disponível 
em: <http://kremlin.ru/events/president/news/17118>. Acesso em: 24 fev. 2017.

PUTIN, V. Poslanie Prezidenta Federalnomu Sobraniu. (Mensagem do Presidente à Assembleia Nacional). 2014. Disponível em: <http://kremlin.ru/events/president/news/47173>. Acesso em: 23 fev. 2017.

REZANOVA, Z. I. (Org.). Nostalgia po sovetskomu. (Nostalgia soviética). Tomsk: Izdatelstvo Tomskogo Universiteta, 2011, p. 59.

USHAKIN, S. "Mi u prochlogo ne uchimsia, mi im jivem (Nós não estudamos o passado, nós o vivemos Entrevista). 2015. Revista eletrônica "Neprikosnovennii zapas". Disponível em: <http://magazines.russ.ru/nz/2015/4/1lint.html>. Acesso em: 21 fev. 2017. 